\title{
The Effects of Stromal Vascular Fraction Administration in Stimulating Graft Healing Process after Anterior Cruciate Ligament Reconstruction Surgery in Rattus norvegicus
}

\author{
Agung Riyanto Budi Santoso ${ }^{1}$ D, Edi Mustamsir ${ }^{1 *}$, Muhammad Luqman Fadli ${ }^{2}$ D, Krisna Yuarno Phatama ${ }^{1}$, Anindita E. P. \\ Wijaya $^{1}$, Lasa Dhakka Siahaan ${ }^{1}$ iD, Alwy Sugiarto ${ }^{1}$ iD \\ ${ }^{1}$ Department of Orthopaedic and Traumatology, Faculty of Medicine, Universitas Brawijaya, RSUD Dr. Saiful Anwar, Malang, \\ Indonesia; ' Department of Pathology Anatomy, Faculty of Medicine, Universitas Brawijaya, RSUD Dr. Saiful Anwar Malang, \\ Indonesia
}

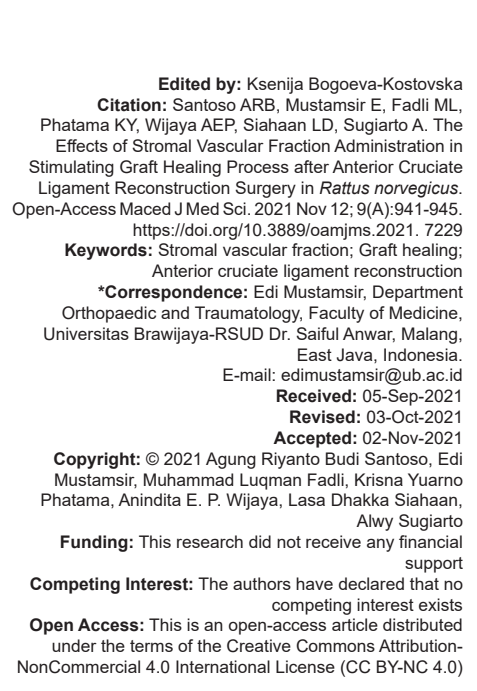

\section{Abstract}

BACKGROUND: Ligament injuries commonly occur in the knee region, and the anterior cruciate ligament (ACL) being the most usually injured. At present, autograft or allograft is the most common material used for ACL reconstruction surgery. The result of the ACL reconstruction depends on the healing process of the graft or ligamentization between graft and bone tunnel.

AIM: This study aims to evaluate the effect of stromal vascular fraction (SVF) intratunnel injection to stimulate graft healing following ACL reconstruction surgery, as measured by histology examination.

METHODS: This study was an experimental laboratory study with a post-test-only control group design using male Rattus norvegicus. A random sampling procedure was used to choose the sample, which was then divided into two groups. The two groups consist of the control group that only had ACL reconstruction surgery and the treatment group that had reconstruction surgery with SVF administration.

RESULTS: This study used advanced ligament maturity index score and showed a significant improvement of graft healing in the treatment group compared to the control group. The measurement is based on the cellular, collagen, and vascular aspect testing with $p<0.05$ for each subscore.

CONCLUSION: SVF intratunnel injection stimulates graft healing after ACL reconstruction surgery and causes a significant increase in cellular, collagen, and vascular aspects in the graft.

\section{Introduction}

Acute injury at the ligament can be consists of sprain and tear, either partial or total. Approximately $30-50 \%$ of ligament injury occurs in sports events [1]. Ligament injury most commonly occurs at the knee, and the most affected ligament is the anterior cruciate ligament $(A C L)$ [2]. The principle therapy of $A C L$ injury varied from immobilization and rehabilitation to stimulate the natural healing process up to reconstruction. The integration of the graft and the bone tunnel, as well as the graft or ligamentization healing phase, determines the outcome of $A C L$ ligament replacement [3]. Many attempts have been made to stimulate both processes, which are expected to reduce the risk of graft failure and accelerate the rehabilitation process.
Stromal vascular fraction (SVF) is a heterogeneous cell population derived from adipose tissue obtained through minimal manipulation of the adipose tissue. SVF contains various cells, including adipose-derived mesenchymal stem cell (AD-MSC), hematopoietic stem cells (HSCs), T regulatory cell), and progenitor cells. The benefits of using adipose tissue as a cell source include a higher number of cells than bone marrow tissue, no age effects, simple and fast tissue collecting and processing, faster proliferative time, and no immunological response in the recipient [4], [5], [6], [7].

The purpose of this research is to see how intratunnel SVF administration improves graft healing after ACL reconstruction surgery, as measured by the advanced ligament maturity index as shown at Table 1 [8]. 
Table 1: Advanced ligament maturity index

\begin{tabular}{|c|c|c|c|c|c|}
\hline \multicolumn{2}{|l|}{ Cell subscore (Total = 8 patients) } & \multicolumn{2}{|l|}{ Collagen subscore (Total = 12 patients) } & \multicolumn{2}{|l|}{ Vessel subscore (Total = 6 patients) } \\
\hline Criteria & Patients & Criteria & Patients & Criteria & Patients \\
\hline Presence of inflammatory cells & & Width of bundles & & Density of blood vessels & \\
\hline Necrosis & 0 & No bundles & 0 & None present & -1 \\
\hline Polymorphonuclear cells & 1 & Width less than $50 \mu \mathrm{m}$ & 2 & More than $200 \%$ present & 0 \\
\hline No inflammatory cells & 2 & Width greater than $50 \mu \mathrm{m}$ & 4 & $150-200 \%$ present & 1 \\
\hline & & & & Less than $150 \%$ present & 2 \\
\hline NAR of fibroblast & & Bundle orientation with long axis of ligament & & Vessel orientation with long axis of ligament & \\
\hline No cells & -1 & No bundles & -2 & No vessels oriented & -2 \\
\hline Average NAR less than 2 (round) & 0 & Less than $50 \%$ oriented & 0 & Less than $30 \%$ oriented & -1 \\
\hline Average NAR 2-4 & 1 & $50-75 \%$ oriented & 2 & Less than $50 \%$ oriented & 0 \\
\hline Average NAR greater than 4 (elongated) & 2 & $75-100 \%$ oriented & 4 & $50-75 \%$ oriented & 1 \\
\hline & & & & $75-100 \%$ oriented & 2 \\
\hline Nucleus of fibroblast aligned with & & Collagen crimp & & Vessel maturity & \\
\hline fascicles and long axis of ligament & & & & & \\
\hline No cells & -2 & No crimp & -2 & No vessel seen & 0 \\
\hline Less than $30 \%$ of cells oriented & -1 & $<25 \%$ crimp & 0 & Capillaries only present & 1 \\
\hline $30-50 \%$ oriented & 0 & $25-75 \%$ crimp & 2 & Arterioles present & 2 \\
\hline $50-75 \%$ oriented & 1 & Crimp with normal length present & 4 & & \\
\hline $75-100 \%$ oriented & 2 & & & & \\
\hline Number of fibroblasts & & & & & \\
\hline None & -1 & & & & \\
\hline Greater than $2 \times$ normal & 0 & & & & \\
\hline Between $1.5 \times$ and $2 \times$ normal & 1 & & & & \\
\hline Less than $1.5 \times$ normal & 2 & & & & \\
\hline
\end{tabular}

\section{Methods}

This research is an experimental laboratory study using a post-test-only control group design. There were divided into two study groups, with each group must have a minimum of nine experimental animals. This group consists of nine Rattus norvegicus rats with only $A C L$ reconstructive surgery formed the control group. The second group was the treatment group, which consisted of nine $R$. norvegicus rats who had $A C L$ reconstructive surgery and were given SVF.

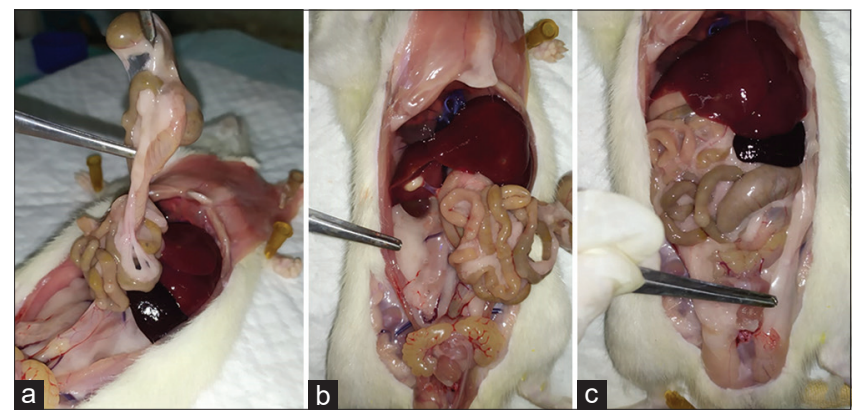

Figure 1: Harvesting of fat tissue. (a) Abdominal fat, (b) perirenal fat (c) epididymal fat

The SVF was made from adipose tissue by sacrificing 5-6-week-old male $R$. norvegicus rats. Adipose tissue was taken perirenal, epididymis, and abdominal fat (Figure 1). The adipose tissues were washed using phosphate-buffered saline (PBS) solution, then crushed to tiny fragments, then immersed using type IA collagenase $0,075 \%$ solution (Sigma-Aldrich) and PBS for $30 \mathrm{~min} 37^{\circ} \mathrm{C}$. Subsequently, the tissues were centrifuged after being filtered with a mesh filter of $100 \mathrm{~m}$ (Sigma-Aldrich). The obtained suspension contains heterogeneous cells estimated to consist of $2 \times 10^{6}$ cells for every $1 \mathrm{ml}$ of suspension (Figure 2) [5], [9].

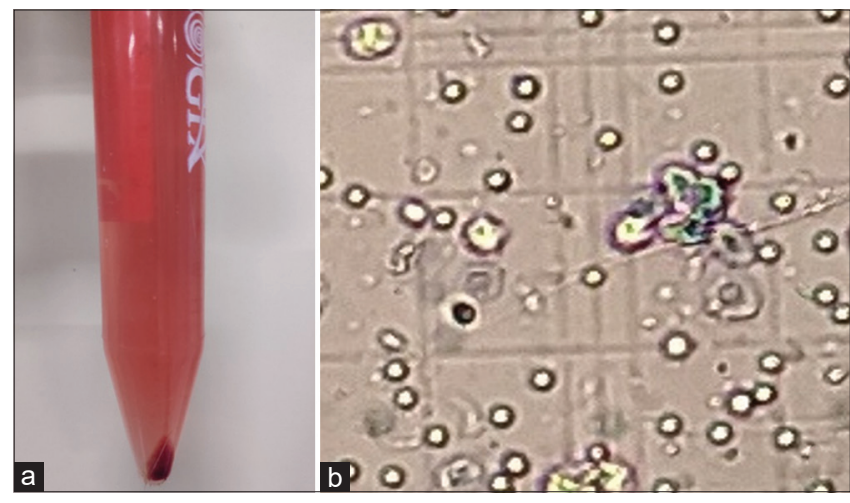

Figure 2: Stromal vascular fraction obtained (a) final suspension, (b) cells count

The patellar tendon was used to repair the $A C L$. A bone tunnel was created on the femur and tibia with 1.6 Kirschner wire, and the graft was placed and secured with 4.0 Vicryl. The femur and tibia tunnels were injected with $0.2 \mathrm{ml}$ SVF. After suturing the skin with 5.0 Prolene, we use plaster of Paris to immobilize the knee joints [10].

The rats were euthanized after 3 weeks, and soft-tissue cleaning was undertaken. Subsequently, the tissue was placed in a $10 \%$ paraformaldehyde solution and then transferred to a $90 \%$ chloride and formic acid solution for decalcification. Samples were made in a paraffin block followed by sectioning and mounting. Staining was performed using hematoxylineosin and Masson trichrome then evaluated under the light microscope. We assess the inflammatory cells (polymorphonuclear cells), fibroblast count, fibroblast nuclear aspect ratio, and cells arrangement for the cellular aspect (Figure 3). There are many points to evaluate the result of this study. First, we evaluate the collagen bundle width, collagen fiber formation, and collagen fiber count for the collagen aspect. The second one, for the vascular factor, we assess vascular density, formation, and maturation. The data collected were tabulated and statistically compared between the 
Table 2: A score of advanced ligament maturity index from the control and treatment groups

\begin{tabular}{|c|c|c|c|c|c|c|c|c|c|}
\hline \multicolumn{5}{|c|}{ Control group } & \multicolumn{5}{|c|}{ Treatment group } \\
\hline \multirow[t]{2}{*}{ Sample } & \multicolumn{3}{|c|}{ Subscore } & \multirow[t]{2}{*}{ Total } & \multirow[t]{2}{*}{ Sample } & \multicolumn{3}{|c|}{ Subscore } & \multirow[t]{2}{*}{ Tota } \\
\hline & Cellular & Collagen & Vascular & & & Cellular & Collagen & Vascular & \\
\hline 1 & 2 & 2 & 3 & 7 & 1 & 8 & 10 & 4 & 22 \\
\hline 2 & 2 & 2 & 2 & 6 & 2 & 6 & 8 & 5 & 19 \\
\hline 3 & 4 & 4 & 1 & 9 & 3 & 8 & 10 & 5 & 23 \\
\hline 4 & 6 & 8 & 3 & 17 & 4 & 8 & 10 & 6 & 24 \\
\hline 5 & 3 & 0 & 0 & 3 & 5 & 6 & 8 & 5 & 19 \\
\hline 6 & -1 & -2 & 0 & -3 & 6 & 6 & 10 & 4 & 20 \\
\hline 7 & 8 & 10 & 5 & 23 & 7 & 8 & 10 & 5 & 23 \\
\hline 8 & 3 & -4 & 2 & 1 & 8 & 7 & 10 & 3 & 20 \\
\hline 9 & 6 & 8 & 4 & 18 & 9 & 6 & 12 & 6 & 24 \\
\hline 10 & 8 & 12 & 6 & 26 & 10 & 8 & 12 & 6 & 26 \\
\hline \multirow[t]{3}{*}{11} & 5 & 8 & 3 & 16 & 11 & 8 & 10 & 6 & 24 \\
\hline & & & & & 12 & 8 & 12 & 6 & 26 \\
\hline & & & & & 13 & 8 & 10 & 6 & 24 \\
\hline
\end{tabular}

control and treatment groups. The Ethics Committee of XXX has approved all animal protocols and all subsequent experiments were carried out according to the relevant guidelines and regulations.

\section{Results}

Evaluation of graft healing was performed using histopathology examination in both the control group and treatment group. The assessment was on cellular, collagen, and vascular aspects (Figure 4). First, we conduct the normality and homogeneity test as the base of the statistic test. Because the data were normally distributed, homogeneous data are not normal after the normality and homogeneity tests. The statistical analysis was performed using the Mann-Whitney non-parametric test.

We found $p=0.002$ based on the results of the analysis using the Mann-Whitney U-test. Because this result was less than $=0.05(p=0.05)$, it may be stated that SVF administration had a significant effect on the graft healing process. Interestingly, based on the test for each subscore, the p-value for cellular was 0.003 , the $p$-value for collagen was 0.002 , and the $p$-value for vascular was 0.002 . All the $p$-values were less than $\alpha=0.05(p<0.05)$, therefore, it can be concluded that there were significant effects of SVF administration toward the improvement in each subscore (Table 2).

\section{Discussion}

A stem cell is one of the preferred therapies for improving graft healing following ACL reconstruction surgery because of its ability to differentiate from other cells according to the appropriate environment. In 2001 and 2002, Zuk reported stem cells in subcutaneous fat tissue and recommended that they be used in cell regeneration therapy [9]. Many studies have used stem cells from such fat tissue to enhance wound healing, antiaging, antifibrosis, and inhibit bone bridge creation in physical fractures. However, no research has been done on the effects of SVF on graft healing especially, after ACL restoration surgery.

The SVF contains heterogeneous mesenchymal cells, including adipose stromal cells, HSC, progenitor cells, endothelial cells, erythrocytes, fibroblast, lymphocytes, monocytes/macrophages, and pericytes. With this cells populations, SVF can regenerate at various cell components using two mechanisms, first by triggering migration, differentiation, and proliferation of recipient cells, and second by paracrine effects.

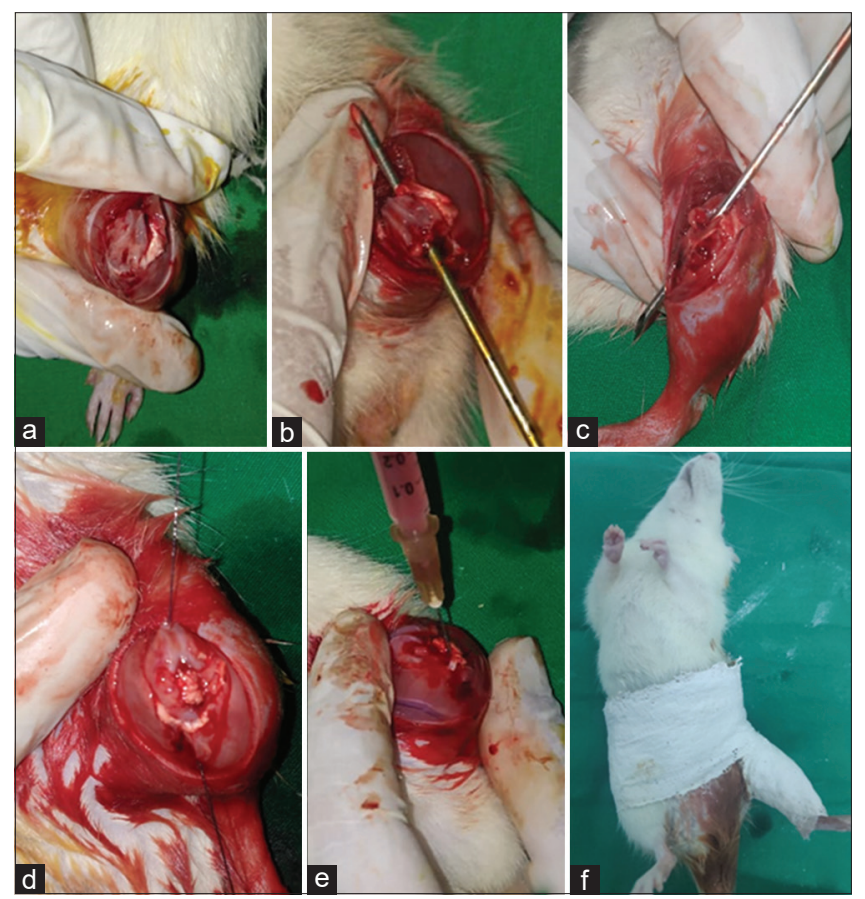

Figure 3: Anterior cruciate ligament reconstruction. (a) Incision, (b) femoral tunneling, (c) tibia tunneling, (d) graft insertion, (e) stromal vascular fraction injection, (f) immobilization using plaster of Paris

There are two studies about SVF study already has been studied, in silico and in vitro by Sananta in 2019. From in silico research, it was concluded that there was some growth factor in SVF including vascular endothelial growth factor (VEGF), transforming growth factor- $\beta$ (TGF- $\beta$ ), insulin-like growth factor-1 (IGF-1), and fibroblast growth factor-2 (FGF-2), which can help further cell regeneration [7]. 
In vitro study by Sananta, 2019, also showed that MSC phenotype characteristic resulted in positive CD-44 and negative CD-45. This result was similar to other studies that SVF contains MSC in the presence of specific surface antigen expression such as CD-44, whereas negative CD-45 showed that the stem cell was originated from adipose cells, not from hematopoietic cells [7].

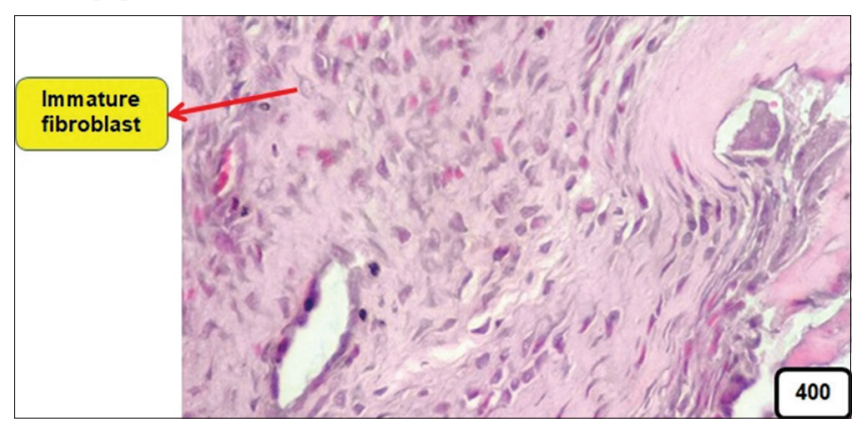

Figure 4: Histological picture of the control group. This picture shows immature fibroblasts with a round-oval nucleus; no arteriole was found

In this study, SVF administration significantly affected the increase of cellular $(p=0.003)$. SVF contains fibroblast and other stromal cells. Thus, SVF increases fibroblast activity and proliferation due to direct transfer of fibroblast from SVF to the recipient, also due to paracrine effect of SVF by secretion of FGF-2, TGF- $\beta$, and IGF-1. On the other hand, SVF also contains T-regulator cells expressing immunosuppression cytokines that act as an immunomodulator and decrease inflammation. This condition is essential in creating a proper environment for graft healing (Figure 5).

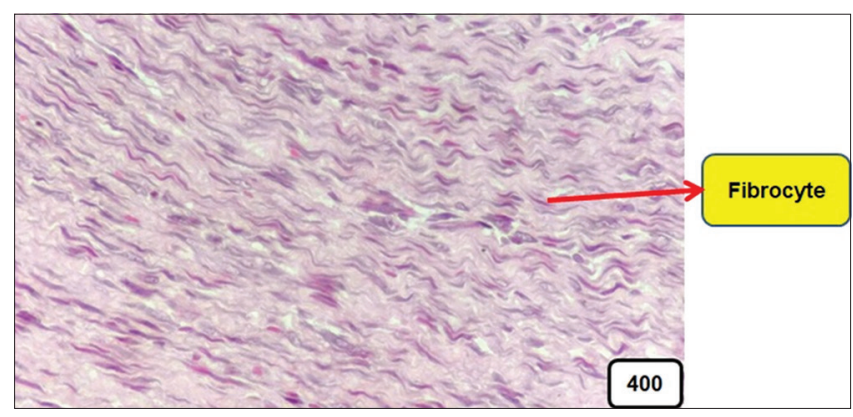

Figure 5: Histological picture of treatment group, dominated by mature fibrocytes

In this study, there were significant effects of SVF administration in increasing collagen on the graft $(p=0.002)$. When administered to graft, SVF may induce recipient cells to increase the synthesis of extracellular matrix proteins such as type I and III collagen to build a scaffold that can accelerate the healing process. This process is mainly rolled by IGF-1 as the key in the graft healing process.

After ACL reconstruction, the vascular graft supply is minimal, mainly only at the midsubstance, increasing the risk of degeneration or graft rupture. Therefore, the SVF ability to stimulate angiogenesis and neovascularization plays an important role in graft healing (Figure 6). In this study, there were significant effects of SVF administration in enhancing vascularization on the graft $(p=0.002)$. This result was similar to the theory mentioning that SVF has several angiogenic components. The SVF angiogenesis ability resulting from the combination of adipose stem cells, macrophage, and fibroblast. Endothelial cells and pericytes also help to develop, stabilize, and remodel this new vascular tissue. On the other hand, SVF also stimulates the angiogenesis process by paracrine, which secreting growth factors including VEGF, hepatocyte growth factor, TGF- $\beta$, and platelet-derived growth factor- $\beta$.

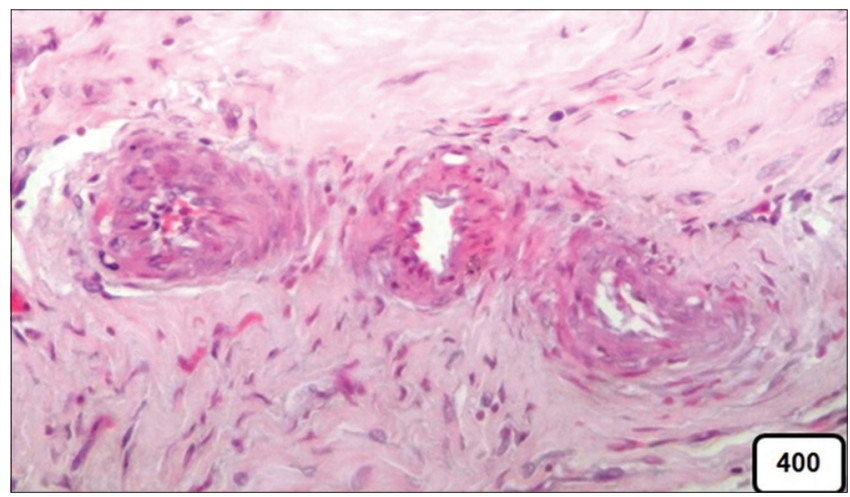

Figure 6: Arterioles were found in the treatment group

This study had several limitations, which only evaluated the graft healing process in the midsubstance and did not evaluate the integration process between graft and bone. Moreover, we only assess the graft healing process for 3 weeks, transitioning from inflammation to proliferation process. We suggest that a histologic study would be conducted to assess the effect of SVF injection on the development of Sharpey's fiber in the bone-tendon interface, determine the optimum time for SVF administration, and determine the optimum temperature for SVF storage. We also suggest that a biomechanic study should be performed to prove the effect of intratunnel SVF injection in stimulating graft healing.

\section{Conclusion}

This study concludes that intratunnel injection of SVF after ACL reconstruction surgery stimulates graft healing and causes a significant increase in cellular, collagen, and vascular aspects in the graft.

\section{References}

1. Shin EH, Kim M, Hada B, Oh CT, Jang MJ, Kim JY, et al. Effects of human placenta extract (Laennec) on ligament healing in a rodent model. Biol Pharm Bull. 2019;42(12):1988-95. https://doi. 
org/10.1248/bpb.b19-00349

PMid:31787714

2. Kaeding CC, Leger-St-Jean B, Magnussen RA. Epidemiology and diagnosis of anterior cruciate ligament injuries. Clin Sports Med. 2017;36(1):1-8. https://doi.org/10.1016/j.csm.2016.08.001 PMid:27871652

3. Sun Y, Chen W, Hao Y, Gu X, Liu X, Cai J, et al. Stem cellconditioned medium promotes graft remodeling of midsubstance and intratunnel incorporation after anterior cruciate ligament reconstruction in a ratmodel. Am J Sports Med. 2019;47(10):232737. https://doi.org/10.1177/0363546519859324 PMid:31306585

4. Rodriguez JP, Murphy MP, Hong S, Madrigal M, March KL, Minev B, et al. Autologous stromal vascular fraction therapy for rheumatoid arthritis: Rationale and clinical safety. Int Arch Med. 2012;5(1):5. https://doi.org/10.1186/1755-7682-5-5

PMid:22313603

5. Alexander RW. Understanding adipose-derived stromal vascular fraction (AD-SVF) cell biology and use on the basis of cellular, chemical, structural and paracrine components: A concise review. J Prolother. 2012;4(1):e855-69.

6. Prins HJ, Schulten EA, ten Bruggenkate CM, Klein-Nulend J, Helder MN. Bone regeneration using the freshly isolated autologous stromal vascular fraction of adipose tissue in combination with calcium phosphate ceramics. Tissue Eng Regen Med. 2016;5(10):1362-74. http://doi.org/10.5966/ sctm.2015-0369

PMid:27388241

7. Sananta P. Pengaruh Pemberian SVF (Stromal Vascular Fraction) dan Scaffold Untuk Mencegah Pembentukan Bony Bridge Pada Growth Plate Injury. Disertasi FK. Indonesia: Universitas Brawijaya: Malang. 2019

8. Biercevicz AM, Proffen BL, Murray MM, Walsh EG, Fleming BC. $\mathrm{T}^{*}$ relaxometry and volume predict semi-quantitative histological scoring of an ACL bridge-enhanced primary repair in a porcine model. J Orthop Res. 2015;33(8):1180-7. http://doi. org/10.1002/jor.22874

PMid:25764143

9. Zuk P. Adipose-derived stem cells in tissue regeneration: A review. ISRN Stem Cells. 2013;2013(1):1-35. http://doi. org/10.1155/2013/713959

10. Leong NL, Kabir N, Arshi A, Nazemi A, Wu BM, McAllister DR, et al. Athymic rat model for evaluation of engineered anterior cruciate ligament grafts. J Vis Exp. 2015;97:52797. http://doi. org/10.3791/52797

PMid:25867958 